\title{
Lipid Peroxidation
}

National Cancer Institute

\section{Source}

National Cancer Institute. Lipid Peroxidation. NCI Thesaurus. Code C81870.

The degradation of lipids caused by an oxidative attack from free radicals. 